\title{
Recurrent pain of a pseudotabetic variety after laminectomy for lumbar disc lesion
}

\author{
GRAHAM MARTIN \\ From the Neurosurgical Unit, Wellington Hospital, New Zealand
}

SUMMARY A variety of pain resembling the lightning pains of tabes dorsalis is described in patients suffering from persistent sciatica, following laminectomy for lumbar disc disease. It occurs in about $13 \%$ of those complaining of post-laminectomy pain and in $5 \%$ of all those having a laminectomy for disc disease. It is associated with damage to the nel ve root and may be precipitated by nerve root resection. About half the patients may get some relief from carbamazepine or clonazepam and the syndrome shows a tendency to improve gradually over three to five years.

Brain $^{1}$ described the pain of tabes dorsalis as "pain ... stabbing in character, brief paroxysms, localised to one spot as though a sharp object was being driven into the limb, each attack lasts only a few seconds, but may recur repeatedly in the same place, or shift from place to place." Fourteen patients who had similar attacks of pain were found among 29 patients with chronic sciatica following laminectomy for a lumbar disc lesion.

\section{Clinical observations}

The 14 patients all complained of a localised jabbing pain fitting the above description; $57 \%$ described it as occurring in showers or episodes, $79 \%$ commented that it was particularly likely to occur at night, $43 \%$ said it was often precipitated by movement.

There was a background of constant pain or hyperaesthesia in $64 \%$ and anaesthesia or hyperaesthesia could be demonstrated in the involved dermatomes. Compared with the other 15 patients who had sciatica, but no lightning pains, motor loss in the involved nerve segments tended to be more marked.

The only major difference between this pain and the lightning pains of tabes dorsalis, is that

\footnotetext{
Address for reprint requests: Dr Graham Martin, Wellington Hospital, Riddiford Street, Newtown, Wellington 2, New Zealand.

Accepted 6 December 1979
}

only one-third of our patients were free of background pain, whereas the absence of background pain is the rule in tabes dorsalis.

\section{Discussion}

The pain generally began within the first month of the last operation, and appeared to improve gradually over the next three to five years, though one patient had the syndrome for ten years, and one person only had one nocturnal attack.

The pain and its response to carbamazepine (see below) have been described before by Dunsker ${ }^{2}$ who described five patients with the "flashing pain syndrome"; three of these had had a lumbar laminectomy and two a cervical disc lesion. Selecki $\mathbf{i}^{3}$ described an "electric current like pain" in an unspecified number of his patients undergoing nerve root section for chronic sciatica.

Under the term "lightning pains", a similar pain was described in hereditary sensory neuropathy by Denny-Brown. ${ }^{4}$ A similar type of pain has been described in familial amyloid neuropathy. ${ }^{56}$

This pain probably arises from damage to the posterior root or ganglion. Dorsal root and ganglion fibrosis have been described in tabes dorsalis, ${ }^{7}$ and also in patients having dorsal root section for chronic sciatica. ${ }^{3}$ There is neuronal loss in the ganglion in hereditary sensory radicular neuropathy. ${ }^{4}$ Two of our patients were 
known to have arachnoiditis, and scarring around the extra-dural nerve root is inevitable after a laminectomy. Four of the patients had their pain precipitated by nerve root section, three by extra-dural nerve root section and one by intradural posterior root section.

There are obvious similarities of this pain to that of trigeminal neuralgia, in which lesions in the nerve root entry zone have been described ${ }^{8}{ }^{9}$ and it is suggested that changes in the ganglion are secondary. In tabes dorsalis, the root entry zone is especially affected. ${ }^{7}$ Arachnoiditis and posterior root section appear to be associated with the pain here so the site of production of the pain also may be in the root entry zone.

Recognition of this syndrome is important as it may respond to carbamazepine; here it responded in four out of the eight who tried it. It seemed that the dosage needed to be closer to the toxic range than is usually needed for tic douloureux, and two more patients obtained some relief, but could not tolerate the side effects of the drug. Carbamazepine was found to be of no value in nerve root pains where the pseudotabetic element was absent. Clonazepam was tried in two patients who did not tolerate carbamazepine and was successful in one. The pain of tabes dorsalis has been reported as responding to carbamazepine. ${ }^{10}$

Nerve root section for tabes dorsalis has been reported as regularly ending in failure ${ }^{11} 12$ and we noted that the syndrome was precipitated by rhizotomy. However, two of the 14 patients with pseudotabetic pain were submitted to operation in order to cure it; one was cured by nerve root section and the other by removing a disc protrusion compressing the root.

\section{Conclusion}

It is suggested that the term pseudotabetic pain be used for this type of pain, because it appears to be a specific variant of chronic pain, with a common pathology of damage to the dorsal root ganglion or posterior root, and because $50 \%$ respond to a specific treatment, carbamazepine.

\section{References}

1 Brain WR. Diseases of the Nervous System. London, 1962, Oxford University Press

2 Dunsker SB, Mayfield FH. Carbamazepine in the Flashing Pain Syndrome. J Neurosurg 1976; 45:49-51.

3 Selecki BR, Tait-Smith A, Mellick R. Neurotomy and Rhizotomy for intractable root pain of lumbar disc origin, experience with 17 patients. Reprinted papers, 46th Scientific Meeting, 1973, Royal Australasian College of Surgeons, Singapore.

4 Denny-Brown D. Hereditary sensory radicular neuropathy. J Neurol Neurosurg Psychiatry $1951 ; 14: 237-52$.

5 Andrade C. A peculiar form of peripheral neuropathy. Brain 1952; 75:408-20.

6 Chambers RA, Medd WE, Spencer H. Primary amyloidosis. Quart J Med 1958; 27:207-26.

7 Schmidt RP, Gonyea EF, Neurosyphilis. Clinical Neurology, vol 2, ch 19, p9-10. Ed Baker AB, Baker LH, New York, 1976, Harper \& Row.

8 Jannetta PJ. Microsurgical approach to the trigeminal nerve for tic doloreux. Prog Neurol Surg 1976; 7:180-200.

9 Olofson RA, Rushton JG, Sayre GP. Trigeminal neuralgia in a patient with multiple sclerosis, autopsy report. J Neurosurg 1966; 24:755-9.

10 Ekbom K. Carbamazepine in the treatment of tabetic lightning pains. Arch Neurol 1972; 26: 374-8.

11 Foerster O. Die Leitungsbahnen des Schmerzgefühls und die Chiurgische Behandlung der Schmerzzustände. Berlin, 1927, Urban und Schwarzenburg.

12 Sindou M, Fischer G, Mansuy L. Posterior spinal rhizotomy and selective posterior rhizidiotomy. Prog Neurol Surg 1976; 7:201-50. 